\title{
EL RETO (VIRTUAL Y REAL) COMO MÉTODO DE ENSEÑANZA- APRENDIZAJE DE LA HISTORIA DEL ARTE
}

The challenge (virtual and real) as a teaching and learning method in Art History

O desafio (real e virtual) como método na aprendizagem da História da Arte

Proyecto de Innovación Docente Innovación y transversalidad: aplicación del aprendizaje colaborativo al patrimonio arquitectónico y el urbanismo en Castilla y León (III).

\section{Joaquín García Nistal}

Universidad de León, España. Teléfono: +34 987291068. Correo electrónico: jgarn@unileon.es

\section{Resumen}

El presente trabajo pretende exponer las características y resultados de un tipo de actividades, basadas en la propuesta de retos y el apoyo de la plataforma Moodle, que hemos aplicado durante los últimos años en asignaturas del Grado en Historia del Arte y del Máster en Cultura y Pensamiento Europeo y que han resultado efectivas para el desarrollo de destrezas e implicación activa de los alumnos. Estos desafíos se estructuran en diferentes niveles de dificultad, estimulan la competitividad entre grupos y “obligan” al alumnado a visitar la arquitectura y manifestaciones artísticas de la ciudad de León para poder resolverlos con éxito.

Palabras clave: estrategias de enseñanza-aprendizaje; reto; Historia del Arte

\begin{abstract}
The main objective of this paper is to show the results of certain activities based on the proposal of goals with the support of the Moodle platform that we have applied during the last few years in the undergraduate courses of Art History and the Masters degree program course in "Cultura y Pensamiento Europeo" (European Culture and Thought) that have been successful for the development of the students` skills and their active involvement. These challenges are structured on different levels of difficulty and stimulate the competitiveness between the groups of students, as well as oblige them to


visit the architecture and artistic manifestations in the city of León enabling them to solve challenges successfully.

Keywords: teaching and learning strategies; challenge; Art History

\section{Resumo}

Este trabalho tem como intuito a exposição das características e dos resultados de um tipo de atividade fundamentada na proposta dos retos e apoios da plataforma Moodle; em prática ao longo dos últimos anos em disciplinas do Grau em Historia da Arte e do Mestrado em Cultura e Pensamento Europeu, que se têm mostrado efetivas para o desenvolvimento das competências e participação ativa dos estudantes. Estes desafios estruturam-se em diferentes níveis de dificuldade, o que estimula a competitividade entre os grupos de estudiantes e os força visitar a arquitetura e manifestações artísticas da cidade de Leão, para assim ser estes desafios poder ser resolvidos com garantias.

Palavras-chave: estratégia de ensino-aprendizagem; desafio; Historia da Arte

\section{Introducción}

Hoy resulta evidente que la implantación del EEES ha ido despertado una conciencia sobre la renovación de las metodologías docentes y los sistemas de evaluación que, como profesores, también ha redefinido nuestros roles y nos compromete a desarrollar tareas que motiven e impliquen activamente al alumnado y que nos permitan el desarrollo de competencias y su evaluación (Casas y Gregorio, 2014).

En este sentido, como docentes inmersos en la adaptación de los estudios en Historia del Arte de la Universidad de León desde el Plan Piloto de adaptación a los nuevos títulos del curso académico 2008/2009, hemos asistido a los titubeos iniciales que han ido dando paso a un compromiso cada vez más firme del profesorado por renovar las estrategias de enseñanza-aprendizaje.

En nuestro caso, conscientes de la necesidad y beneficios de la aplicación de las TIC en el aula (Pablos, 2010; Alejandre, 2015) y del trabajo colaborativo en la resolución de problemas (Villegas, 2014), hemos diseñado y aplicado en algunas de las asignaturas del doble Grado en Historia e Historia del Arte y en el Máster Universitario en Cultura y Pensamiento un tipo de retos que, dotados de niveles 
graduales de dificultad, tienen como objetivo fomentar la participación activa de los estudiantes y su comunicación horizontal, así como el desarrollo de su capacidad creativa, analítica y crítica.

\section{Contextualización}

La aplicación de este tipo de retos o desafíos en asignaturas como "Iconografía religiosa” (6 European Credit Transfer and Accumulation System -ECTS-), que tiene la particularidad de impartirse al mismo tiempo en el primer curso del Grado en Historia del Arte y el tercer curso del doble Grado en Historia e Historia del Arte, y "la antigüedad clásica y el simbolismo en el arte occidental” (5 ECTS) del Máster universitario en cultura y pensamiento: tradición y pervivencia, nos ha permitido evaluar positivamente el alto grado de versatilidad, transferibilidad y resultados formativos de esta propuesta metodológica, a pesar de aplicarse en niveles educativos dispares (Grado-Máster) y a un número de alumnos desigual y base formativa variable (en el caso del Máster a alumnos procedentes de distintas áreas de conocimiento).

Por otra parte, las características de estos retos vienen determinadas en buena medida por las de la propia plataforma Moodle en que han sido diseñados, ya que esta herramienta -calificada como tecnología colaborativa (Pérez y otros, 2009)- facilita el desarrollo de proyectos colaborativos e intercambio de materiales entre estudiantes y/o entre profesor y estudiantes.

\section{Diseño y desarrollo}

Estos retos son diseñados en primera instancia por el profesor, planteados para grupos reducidos -idealmente de tres o cuatro alumnos-, y culminan con el diseño de otros por parte del alumnado, que, de este modo, se convierte en el creador de nuevos contenidos, quien determina la dificultad de las actividades y autorregula el aprendizaje, como ha señalado Rodríguez (2008). Los desafíos parten de un caso concreto y real y están estructurados en niveles de dificultad progresiva a fin de facilitar también una formación gradual. Asimismo, la superación de un nivel otorga el acceso "exclusivo” a nueva información gráfica y escrita que permite afrontar el siguiente nivel del reto, generando así necesidades de adquisición de información que estimulan la implicación activa de los estudiantes. 


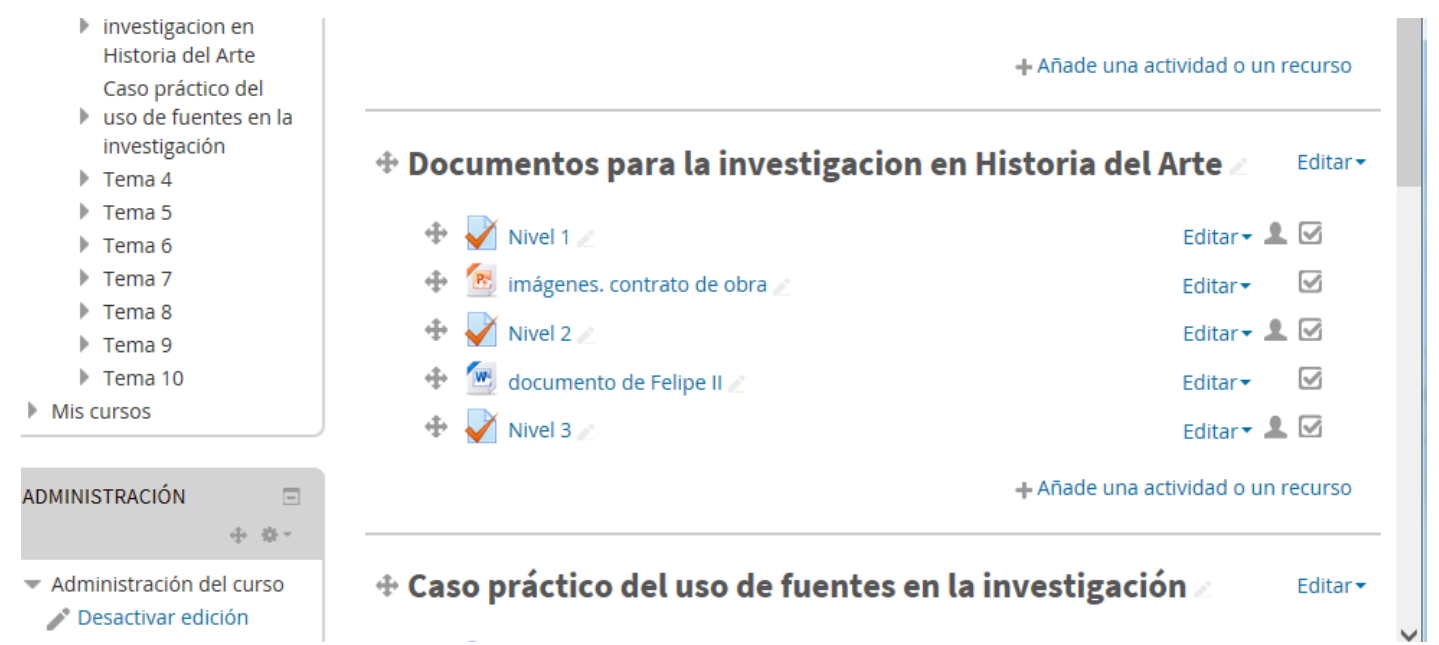

Figura 1.

Imagen de una actividad en la plataforma Mooodle con tres niveles de dificultad

Como ejemplo, para dar a conocer la utilidad de los documentos históricos en la investigación de la Historia del Arte, ofrecemos como punto de partida la transcripción de un contrato de obra del siglo XVI. El primer reto al que se enfrentan los grupos consiste en revelar, mediante el análisis del documento y gracias a la información explícita que contiene, a qué obra se hace referencia y cuál es su ubicación concreta.

La superación de este primer nivel se "recompensa” con el acceso a nueva información sobre la obra artística, esta vez gráfica, y que resulta imprescindible para responder a un nuevo cuestionario, esta vez dotado de preguntas más complejas y donde el alumnado debe hacer frente al análisis de datos implícitos (ya no explícitos) y el cotejo imagendocumento.

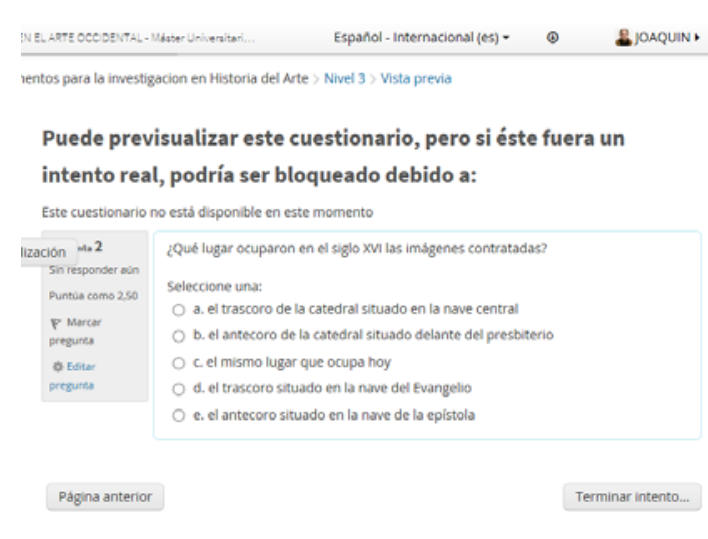

Figura 2.

Modelo de pregunta del cuestionario

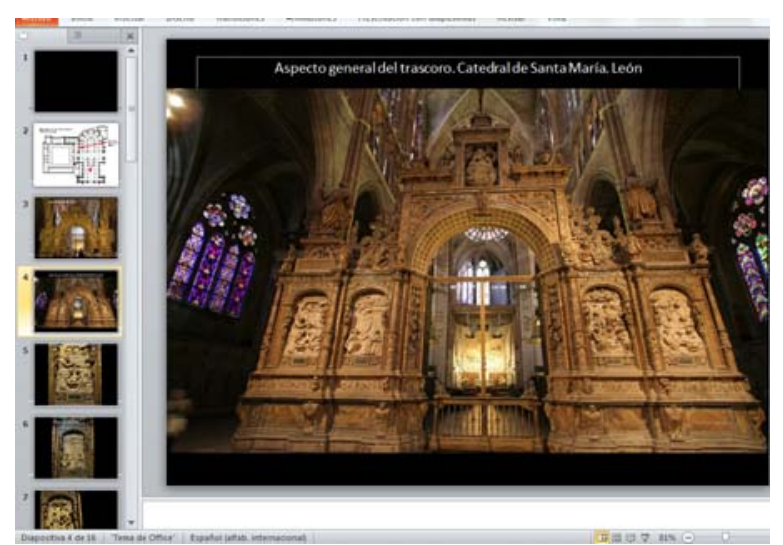

Figura 3.

Carpeta de contenidos gráficos de acceso restringido

El reto (virtual y real) como método de enseñanza-aprendizaje de la Historia del Arte 
Por último, aunque el número de niveles puede incrementarse, los grupos que han superado las pruebas anteriores tienen acceso a nueva documentación que les llevará a enfrentarse a un desafío final, formulado a través de una pregunta que sólo puede ser resuelta mediante la visita física de la obra y el análisis de la nueva información. Siguiendo este modelo, se insta a los diferentes grupos a diseñar retos propios para el resto de grupos y que de esta forma, en palabras de Zabalza (2004), alcancen protagonismo en el proceso de enseñanza-aprendizaje

\section{Evaluación y conclusiones}

La puesta en práctica de este sistema de retos de dificultad gradual incrementa sobresalientemente la participación del alumnado, fomenta el uso de las tecnologías web y los acerca a la realidad arquitectónica y artística del entorno próximo. Además, lejos de acometer el aprendizaje de contenidos concretos, permite generar habilidades como el análisis crítico de documentos e imágenes y aplicar el método inductivo. Por otra parte, este modelo de desafíos alcanza mayor fortuna cuando son diseñadas por los propios alumnos para otros grupos, ya que fomentan el aprendizaje autónomo, desarrollan su creatividad y los convierte en protagonistas del proceso de enseñanzaaprendizaje.

Por último, la naturaleza gradual y abierta de este diseño de retos lo convierte en un modelo transferible a cualquier área de conocimiento; basta con crear cuestionarios de diferentes niveles de dificultad, acompañarlos con carpetas de información restringidas a los grupos que superan las fases precedentes y que se plantee un desafío final que requiera un acercamiento a la realidad objeto de estudio.

\section{Referencias}

Alejandre, J. L. (Coord.) (2016). Buenas prácticas en la docencia universitaria con apoyo de TIC: experiencias en 2015. Zaragoza: Universidad de Zaragoza.

Casas Agudo, D., \& Gregorio Cano, A. (2014). Implicaciones del nuevo paradigma educativo: Retos ante el EEES. En C. Salgado Santamaría (Coord.), Aplicación del EEES a las necesidades docentes (pp. 111-130). Madrid: Visión Libros.

Pablos, J. de (2010). Políticas educativas y la integración de las TIC a través de buenas prácticas docentes. En J. de Pablos Pons y otros (Coords.) Políticas educativas y buenas prácticas con TIC (pp. 21-43). Barcelona: Graó. 
Pérez, M. T., Martín García-Arista, M. Á., Arratia García, O., \& Galisteo González, D. (2009). Innovación en la docencia universitaria con Moodle. Casos prácticos. Alicante: Club Universitario.

Rodríguez, L. (2008). Autorregulación en el aprendizaje. En A. Escribano \& A. del Valle (Coords.), El aprendizaje basado en problemas. Una propuesta metodológica en Educación Superior (pp. 53-70). Madrid: Nerea.

Villegas, J. (2014). El ABP rediseñado. Una versión personal del Aprendizaje Basado en Problemas. Bloomington: Palibrio.

Zabalza, M. Á. (2004). La enseñanza universitaria. El escenario y sus protagonistas. Madrid: Narcea. 